\title{
Complete atrioventricular septal defect: Outcome of pulmonary artery banding improved by adjustable device
}

\author{
Ramana Rao V. Dhannapuneni, MD, FRCS, Gordon Gladman, MBChB, MRCP, \\ Stephen Kerr, MBBS, RACP, Prem Venugopal, MCh, FRCS, Nelson Alphonso, MD, FRCS, and \\ Antonio F. Corno, MD, FRCS, FACC, FETCS
}

\begin{abstract}
Objective: We sought to evaluate pulmonary artery banding in infants with complete atrioventricular septal defects.

Methods: From 2000 to 2009, 20 infants with complete atrioventricular septal defects underwent pulmonary artery banding because of unsuitable anatomy (unbalanced ventricles, associated lesions, or both) or clinical condition (infection, chronic lung disease, or noncardiac malformation). Patients were divided into 2 groups: the conventional PAB group $(n=13$ [65\%]; mean age, $74 \pm 56$ days [range, 6-187 days]; mean weight, $3.3 \pm$ $1.1 \mathrm{~kg}$ [range, $2.1-5.8 \mathrm{~kg}])$ and the FloWatch-PAB group $(\mathrm{n}=7$ [35\%]; mean age, $111 \pm 40$ days [range, 81-187 days]; mean weight, $4.3 \pm 1.2 \mathrm{~kg}$ [range, 3.2-6.1 kg]). There was no statistical difference in age or weight. Preoperative mechanical ventilation was required in $3(23 \%)$ of 13 infants in the conventional PAB group and $5(71 \%)$ of 7 infants in the FloWatch-PAB group $(P<.05)$.
\end{abstract}

Results: Ten $(77 \%)$ of 13 infants in the conventional PAB group died versus $0(0 \%)$ of 7 infants in the FloWatch-PAB group $(P<.001)$. Sternal closure was delayed in $6(46 \%)$ of 13 infants in the conventional $\mathrm{PAB}$ group and $0(0 \%)$ of 7 infants in the FloWatch-PAB group $(P<.05)$. The mean duration of mechanical ventilation, intensive care unit stay, and hospital stay was significantly longer $(P<.05)$ in the conventional PAB group than in the FloWatch-PAB group ( $21 \pm 17$ days [range, 4-61 days] vs $3 \pm 2$ days [range, 1-8 days], $22 \pm$ 18 days [range, 5-61 days] vs $7 \pm 6$ days [range, 2-21 days], and $54 \pm 12$ days [range, 40-71 days] vs $29 \pm 25$ days [range, 9-81 days], respectively). Left atrioventricular valve regurgitation increased (mild to moderate) in 2 infants in the conventional PAB group and decreased (severe to moderate) in 2 infants in the FloWatch-PAB group. Six of 10 survivors ( 1 in the conventional PAB group and 5 in the FloWatch-PAB group) underwent pulmonary artery debanding and repair after a median interval of 125 days (range, 34-871 days); 4 of 10 are awaiting repair.

Conclusions: In selected patients with complete atrioventricular septal defects, pulmonary artery banding followed by late repair is a viable alternative strategy. In our study the FloWatch-PAB device resulted in improved survival and made later repair possible in a better clinical state. (J Thorac Cardiovasc Surg 2011;141:179-82)

Primary repair is now the treatment of choice for infants with complete atrioventricular septal defects (cAVSDs) to prevent irreversible pulmonary hypertension. Because thickening of the media of the small pulmonary arteries can occur by 6 months of age, primary repair is generally performed before this time to prevent pulmonary vascular obstructive disease. ${ }^{1}$ Various reports have demonstrated safe and effective repair in infants with cAVSDs within the first few months of life. ${ }^{2-8}$

\footnotetext{
From the Cardiac Unit, Alder Hey Children NHS Foundation Trust, Liverpool, United Kingdom.

Disclosures: Antonio F. Corno reports consulting fees from Allergan, the manufacturer of the Flo Watch band.

Accepted for presentation at the 20th Meeting of the Association of Thoracic and Cardiac Surgeons of Asia, Seoul, Korea, October 26-29, 2009.

Received for publication Sept 26, 2009; revisions received Feb 22, 2010; accepted for publication March 14, 2010; available ahead of print July 2, 2010.

Address for reprints: Antonio F. Corno, MD, FRCS (Glasgow), FACC, FETCS, Pediatric Cardiac Surgery, Prince Salman Heart Center, King Fahad Medical City, PO Box 59046, Riyadh 11525, Kingdom of Saudi Arabia (E-mail: acorno@kfmc.med.sa). $0022-5223 / \$ 36.00$

Copyright (C) 2011 by The American Association for Thoracic Surgery doi:10.1016/j.jtcvs.2010.03.047
}

Some children with cAVSDs are not suitable for early primary repair. Reasons include (1) unfavorable intracardiac anatomy, such as unbalanced ventricular morphology; (2) associated noncardiac anomalies, such as exomphalos; (3) poor clinical status contraindicating cardiopulmonary bypass because of active respiratory tract infection frequently requiring prolonged mechanical ventilation, sepsis, severe renal and/or liver dysfunction, or gastrointestinal or neurological complications; and (4) late presentation with severe reactive pulmonary hypertension. In these situations primary repair is a high-risk procedure. Palliation with pulmonary artery banding $(\mathrm{PAB})$ followed by later repair is an alternate surgical option. ${ }^{9-15}$ PAB has been demonstrated to be effective, particularly in the presence of advanced pulmonary hypertension ${ }^{16}$; however, its role in infants has always been associated with high mortality and morbidity in the past, ${ }^{17}$ as well in recent literature. ${ }^{13,18}$

The purpose of this study was to evaluate the current role of PAB in infants with cAVSDs, with particular focus on outcome and its effect on the degree of atrioventricular valve 


\section{Abbreviations and Acronyms \\ cAVSD $=$ complete atrioventricular septal defect \\ $\mathrm{PAB}=$ pulmonary artery banding}

regurgitation, both of which have been considered potential drawbacks to PAB. ${ }^{17}$ The results of conventional PAB with a Teflon band fixed around the pulmonary artery have been compared with results obtained with a telemetrically adjustable FloWatch-PAB device (Allergan, Lausanne, Switzerland), which has already been successfully used in the management of infants with atrioventricular septal defect and other congenital heart defects. ${ }^{19-24}$

\section{MATERIALS AND METHODS}

In a retrospective study we reviewed the data of 20 consecutive infants ( $<1$ year of age) with cAVSDs who, between 2000 and 2009, underwent $\mathrm{PAB}$ instead of primary repair because of unsuitable intracardiac anatomy (unbalanced ventricles, associated lesions, or both in 10 infants) and/or poor clinical condition (continuous chest infections with positive infection markers and positive cultures, despite appropriate respiratory and antibiotic treatment, contraindicating cardiopulmonary bypass in 10 infants, with 8/10 requiring preoperative mechanical ventilation). Children older than 1 year of age with cAVSDs with late presentation and severe pulmonary hypertension were excluded. The adjustable FloWatch-PAB device was introduced in our institute on 2004, and surgical preference was the only determinant between conventional PAB and FloWatch-PAB. Patients were entered in one of the 2 groups depending on the type of PAB used. In the same period 141 patients with cAVSDs underwent complete repair. The criteria of indication for PAB instead of primary repair in 20 infants (20/161 [12\%]) remained the same through the study period, as did the surgical approach (median sternotomy for all infants) and the preparation of the pulmonary artery. The only difference between the 2 groups was the use of the Teflon band, which was premeasured according to the Trusler rule as a starting point, in the group with conventional PAB and the implantation of the adjustable FloWatch-PAB device in the FloWatch-PAB group. In the conventional $\mathrm{PAB}$ group, after the provisional fixation of the band according to the Trusler rule, the final tightening of the band was adjusted by measuring the distal pulmonary artery pressure and the arterial oxygen saturation. In the FloWatch-PAB group the device, available in a single size, was simply implanted in a totally open position, and tightening was performed gradually over the following days, always by means of remote control, with measurement of the transband velocity with Doppler echocardiographic analysis.

Table 1 reports the characteristics of the patient population. There was no statistical difference between the 2 groups in age and body weight. Preoperative mechanical ventilation was required less frequently in the conventional PAB group $(P<.05)$. Down syndrome was present in $5(38 \%)$ of 13 infants in the conventional PAB group and $6(86 \%)$ of 7 infants in the FloWatch-PAB group.

Data were reviewed for (1) hospital mortality (defined as death within 30 days after the operation, in the hospital during the same admission, or in the referring hospital when an infant was transferred back to the referring hospital instead of being discharged); (2) delayed sternal closure because of hemodynamic instability; (3) number of required PAB adjustments; (4) duration of mechanical ventilation; (5) intensive care unit stay; (6) hospital stay; (7) degree of atrioventricular valve regurgitation (classified as absent, mild, moderate, or severe based on echocardiographic analysis before surgical intervention and at last control); and (8) debanding at the time of repair.
The 2 groups were compared with paired Student's $t$ and $\chi^{2}$ tests. The retrospective study has been approved by the institutional review board.

\section{RESULTS}

Table 2 reports the observed results. A statistically significant difference between the 2 groups, conventional PAB versus FloWatch-PAB, was observed with regard to hospital mortality $(P<.001)$, delayed sternal closure $(P<.05)$, duration of postoperative mechanical ventilation $(P<.05)$, duration of postoperative intensive care unit stay $(P<.05)$, and postoperative hospital stay $(P<.05)$.

Cause of death was cardiorespiratory failure in 4 infants, multiorgan failure in 2 infants, aspiration pneumonia in 1 infant, and overwhelming sepsis in 1 infant; 2 infants died after transfer back to the referral hospital, and the cause of death remained unknown.

Five $(83 \%)$ of the 6 infants with delayed sternal closure died, with 4 of 5 requiring surgical adjustment of conventional $\mathrm{PAB}$ with a reoperation in the intensive care unit. $\mathrm{A}$ total of 44 telemetric FloWatch-PAB adjustments (41 to tighten and 3 to release the pulmonary artery) were required in all 7 infants in the FloWatch-PAB group (mean, 6.5 adjustments per patient), always by means of remote control, with measurement of the transband velocity with Doppler echocardiographic analysis.

The degree of left atrioventricular valve regurgitation was unchanged in the majority of infants but increased in 2 infants (mild to moderate in one and moderate to severe in the other) in the conventional PAB group and decreased (severe to moderate) in 2 infants in the FloWatch-PAB group.

Six of 10 survivors underwent pulmonary artery debanding (1 in the conventional PAB group who required pulmonary artery reconstruction and 5 in the FloWatch-PAB group, none of whom required pulmonary artery reconstruction) and complete repair after a median interval of 125 days (range, 34-871 days). Four of 10 patients are still waiting for repair.

\section{DISCUSSION}

In the past, infants with cAVSDs were initially palliated with $\mathrm{PAB}$ to prevent pulmonary vascular disease, followed by complete repair at a later stage to reduce mortality and morbidity. ${ }^{12,15}$ Substantial improvements in surgical and cardiopulmonary bypass techniques, as well as perioperative care, allowed surgeons to successfully perform early repair of cAVSDs in infants. ${ }^{2-8}$ Nevertheless, there are situations in which early repair in infants is not feasible or is accompanied by unacceptable risk because of the presence of unfavorable intracardiac anatomy (unbalanced ventricles, associated lesions, or both) and/or poor clinical condition (infection, chronic lung disease, or associated noncardiac malformation). In these situations palliation with PAB followed by late repair is recognized as a viable surgical option. ${ }^{9-15}$ 
TABLE 1. Patients' characteristics

\begin{tabular}{lccc}
\hline & $\begin{array}{c}\text { Conventional } \\
\text { PAB }\end{array}$ & FloWatch-PAB & $\begin{array}{c}\text { Statistical } \\
\text { difference }\end{array}$ \\
\hline No. & 13 & 7 & \\
$\begin{array}{l}\text { Mean age, d (range) } \\
\text { Mean weight, }\end{array}$ & $74 \pm 56(6-187)$ & $111 \pm 40(81-187)$ & NS \\
$\quad$ kg (range) & $3.3 \pm 1.1(2.1-5.8)$ & $4.3 \pm 1.2(3.2-6.1)$ & NS \\
$\begin{array}{c}\text { Preoperative } \\
\text { mechanical }\end{array}$ & $3 / 13(23 \%)$ & $5 / 7(71 \%)$ & $P<.05$ \\
$\quad$ & & & \\
\hline
\end{tabular}

$P A B$, Pulmonary artery banding; $N S$, not significant.

PAB is usually not a low-risk procedure, particularly in small infants. Hospital mortality of $8.6 \%$ (47/711 patients) has been reported in the European Congenital Data-Base (www.eactscongenitaldb.org) for all patients who underwent isolated PAB for any congenital heart defect. A mortality rate of $13 \%$ (12/92 patients) has been recorded in the Society of Thoracic Surgeons Congenital Database (www.sts.org) for isolated PAB in patients with cAVSDs, a rate that is significantly higher than for any other congenital heart defect. A similarly high mortality (13. $8 \%$ ) has been reported in the literature for infants with cAVSDs undergoing isolated PAB. ${ }^{13}$

In our retrospective study we observed a major difference in mortality between the 2 groups ( $77 \%$ vs $0 \%$ ), despite the fact that the infants undergoing conventional PAB were generally less sick (lower incidence of a preoperative mechanical ventilation and Down syndrome) than infants treated with the adjustable FloWatch-PAB device.

We tried to analyze the reasons behind this difference in mortality. Historically, when palliation with PAB instead of primary repair was widely used to treat congenital heart defects, the mortality with PAB was higher (59\%) in infants less than 3 months of age when compared with that seen in infants greater than 3 months of age $(21 \%){ }^{17}$ A recent analysis of the Society of Thoracic Surgeons Congenital Heart Database $^{18}$ showed that cardiac surgery in infants with low birth weight is associated with increased mortality. Although there was no statistical difference in age and body weight in our study between the conventional PAB and FloWatch-PAB groups, we analyzed whether deaths in the conventional PAB group occurred more frequently in children with lower age and body weight at the time of the operation: 7 of 10 deaths occurred in infants less than 3 months of age, and 3 of 10 deaths occurred in infants at greater than $3 \mathrm{~kg}$ of body weight. In the group undergoing conventional PAB, $9(69 \%)$ of 13 infants were less than 3 months of age, and $5(38 \%)$ of 13 were at less than $3 \mathrm{~kg}$ of body weight versus $4(57 \%)$ of 7 and $0(0 \%)$ of 7 , respectively, in the FloWatch-PAB group. Because these differences did not reach statistical significance, younger age and lower body weight cannot be considered risk factors for mortality.
TABLE 2. Results

\begin{tabular}{lcrl}
\hline & $\begin{array}{c}\text { Conventional } \\
\text { PAB }\end{array}$ & FloWatch-PAB & $\begin{array}{l}\text { Statistical } \\
\text { difference }\end{array}$ \\
\hline Hospital deaths & $10 / 13(77 \%)$ & $0 / 7(0 \%)$ & $P<.001$ \\
Chest left open & $6 / 13(46 \%)$ & $0 / 7(0 \%)$ & $P<.05$ \\
Mechanical & $21 \pm 17(4-61)$ & $3 \pm 2(1-8)$ & $P<.05$ \\
$\quad$ & & & \\
$\quad$ ventilation, d (range) & & & \\
ICU stay, d (range) & $22 \pm 18(5-61)$ & $7 \pm 6(2-21)$ & $P<.05$ \\
Hospital stay, d (range) & $54 \pm 13(40-71)$ & $29 \pm 25(9-81)$ & $P<.05$ \\
\hline$P A B$, Pulmonary artery banding; $I C U$, intensive care unit. &
\end{tabular}

The difference in mortality between the 2 groups could be partly due to the fact that the initial group of 7 patients operated on until 2004 had been treated with conventional PAB because the FloWatch-PAB device was not yet available. However, the mortality with conventional PAB continued to remain increased $(50 \%)$ in the last 6 years of the study.

Because the indications for surgical intervention and the perioperative management in infants with cAVSDs have not changed over the study period, the surgical technique must contribute to the difference in outcome. Additionally, the postoperative period in the FloWatch-PAB group was smoother, without any requirement for delayed sternal closure and shorter duration of postoperative mechanical ventilation and intensive care unit and hospital stay (Table 2).

These observations are similar to the results previously reported with the FloWatch-PAB device in other congenital heart defects, including preparation for Fontan circulation in univentricular hearts and left ventricular retraining, ${ }^{19-24}$ and, in particular, when compared with conventional PAB. ${ }^{21,22}$ The improved outcomes with the FloWatchPAB device appear to be the consequence of the telemetrically controlled device, which allows repeated graduated tightening of the pulmonary artery band, thereby facilitating a controlled and stepwise reduction of the pulmonary blood flow and pressures. The adjustments, tightening or loosening, can be tailored to the clinical condition of the patient over a protracted period of time, ensuring a smooth early postoperative course. In anesthetized infants it is difficult to instantaneously achieve adequate control of pulmonary blood flow with the application of fixed conventional PAB. Often readjustments of the band are required, either with a reoperation or by leaving the chest open for surgical adjustments in the intensive care unit, which are associated with a substantial risk of mortality and morbidity. The instability of the patient's hemodynamics, mostly caused by labile pulmonary vascular reactivity and modifications in the left-toright intracardiac shunt but also related to the very delicate balance between volume and pressure overload, make the establishment of appropriate and durable tightening extremely difficult. This is particularly so in very sick infants with chronic mechanical ventilation, additional lesions, or both. The FloWatch-PAB device not only eliminates the need 
for reoperation to adjust the band but also provides the ability to precisely and progressively tighten the band over days or weeks when the patient is awake and spontaneously breathing. This can be performed on the ward or outpatient clinic, adjusting the tightening according to the clinical condition and to the transband pressure gradient measured with Doppler echocardiographic analysis. These are the main reasons why the FloWatch-PAB device provides better clinical results than conventional $\mathrm{PAB}$ with shorter intensive care unit and hospital stays, fewer complications, and also subsequent cost reduction. ${ }^{22}$

This study also confirmed an additional advantage of the noncircular shape of the cross-section of the FloWatch-PAB device: reconstruction of the pulmonary artery after debanding is no longer required because the arterial wall remains pliable. ${ }^{21}$ After conventional PAB, the localized fibrosis of the pulmonary artery wall almost always requires an extensive resection with patch reconstruction.

A further historical concern when considering PAB in infants with cAVSDs has been the effect on atrioventricular valve regurgitation; the total biventricular pressure overload generated by $\mathrm{PAB}$ with the common atrioventricular valve connected to both ventricles was considered a potential cause for increasing the degree of atrioventricular valve regurgitation. Our experience has demonstrated that this concern is not justified. In fact, in a few infants there was a substantial reduction in the degree of atrioventricular valve regurgitation because of the progressive reduction in volume overload obtained with the FloWatch-PAB device, with a subsequent reduction in ventricular dilatation.

\section{CONCLUSIONS}

In infants with cAVSDs unsuitable for repair because of intracardiac anatomy, high-risk clinical condition, or both, PAB followed by late repair is a viable alternate surgical option. The use of the adjustable FloWatch-PAB device, resulting in significant hemodynamic improvement by progressively reducing the pulmonary artery pressures and the left-to-right shunt, not only increases survival but also makes delayed repair feasible in a better clinical state, with reduced mortality and morbidity.

We thank Dr Tom Karl, Brisbane, Australia, for his review of the manuscript and his comments.

\section{References}

1. Yamaki S, Yasui H, Kado H, Yonenaga K, Nakamura Y, Kikuchi T, et al. Pulmonary vascular disease and operative indications in complete atrioventricular canal defect in early infancy. J Thorac Cardiovasc Surg. 1993;106:398-405.

2. Dragulescu A, Fouilloux V, Ghez O, Fraisse A, Kreitmann B, Metras D. Complete atrioventricular canal repair under 1 year: Rastelli one-patch procedure yields excellent long-term results. Ann Thorac Surg. 2008;86:1599-604.
3. Kobayashi M, Takahashi Y, Ando M. Ideal timing of surgical repair of isolated complete atrioventricular septal defect. Interact Cardiovasc Thorac Surg. 2007; 6:24-6.

4. Kogon BE, Butter H, McConnell M, Leong T, Kirshbom PM, Kanter KR. What is the optimal time to repair atrioventricular septal defect and common atrioventricular valve orifice? Cardiol Young. 2007;17:356-9.

5. Lacour-Gayet F, Campbell DN, Mitchell M, Malhotra S, Anderson RH. Surgical repair of atrioventricular septal defect with common atrioventricular valve in early infancy. Cardiol Young. 2006;16(suppl III):52-8.

6. Lange R, Guenther T, Bush R, Hess J, Schreiber C. The presence of Down syndrome is not a risk factor in complete atrioventricular septal defect repair. J Thorac Cardiovasc Surg. 2007;134:304-10.

7. Singh RR, Warren PS, Reece TB, Ellman P, Peeler BB, Kron IL. Early repair of complete atrioventricular septal defect is safe and effective. Ann Thorac Surg. 2006;82:1598-601.

8. Suzuki T, Bove EL, Devaney EJ, Ishizaka T, Goldberg CS, Hirsch JC, et al. Results of definitive repair of complete atrioventricular septal defect in neonates and infants. Ann Thorac Surg. 2008;86:596-602.

9. Al Qethamy HO, Aboelnazar S, Aizaz K, Al Faraidi Y. Play safe: band late presenting complete atrioventricular canal. Asian Cardiovasc Thorac Ann. 2002;10: 31-4.

10. Ohashi N, Matsushima M, Maeda M, Yamaki S. Two-stage procedure for pulmonary vascular obstructive disease in Down syndrome with congenital heart disease. Circ J. 2006;70:1446-50.

11. Piluiko VV, Poynter JA, Nemeh H, Thomas RL, Forbes TJ, Delius RE, et al. Efficacy of intraluminal pulmonary artery banding. J Thorac Cardiovasc Surg. 2005; 129:544-50.

12. Silverman N, Levitsky S, Fisher E, DuBrow I, Hastreiter A, Scagliotti D. Efficacy of pulmonary artery banding in infants with complete atrioventricular canal. Circulation. 1983;68:II48-53.

13. Takayama H, Sekiguchi A, Chikada M, Norma M, Ishizawa A, Takamoto S. Mortality of pulmonary artery banding in the current era. Ann Thorac Surg. 2002;74: 1219-24.

14. Yoshimura N, Yamaguchi M, Oka S, Yoshida M, Murakami H. Pulmonary artery banding still has an important role in the treatment of congenital heart disease. Ann Thorac Surg. 2005;79:1463.

15. Williams WH, Guyton RA, Michalik RE, Plauth WH, Zorn-Chelton S, Jones EL, et al. Individualized surgical management of complete atrioventricular canal. J Thorac Cardiovasc Surg. 1983;86:838-44.

16. Yamasaki M, Kawasaki S, Satoh H, Minami K, Hosoda Y, Yamaki S. Repair of complete atrioventricular septal defect with severe pulmonary hypertension. Effect of re-pulmonary artery banding and analysis of lung biopsy: a case report. Jpn J Thorac Cardiovasc Surg. 1998;46:579-82.

17. Hunt CE, Formanek G, Levine MA, Castaneda AR, Moller JH. Banding of the pulmonary artery: results in 111 Children. Circulation. 1971;43:395-406.

18. Curzon CL, Milford-Beland S, Li JS, O'Brien SM, Jacobs JP, Jacobs ML, et al. Cardiac surgery in infants with low birth weight is associated with increased mortality: analysis of the Society of Thoracic Surgeons Congenital Heart Database. J Thorac Cardiovasc Surg. 2008;135:546-51.

19. Bonnet D, Corno AF, Sidi D, Sekarski N, Beghetti M, Schulze-Neick I, et al. Early clinical results of telemetric adjustable pulmonary artery banding FloWatch ${ }^{\circledR}-\mathrm{PAB}$. Circulation. 2004;110:II158-63.

20. Corno AF, Bonnet D, Sekarski N, Sidi D, Vouhé P, von Segesser LK. Remote control of pulmonary blood flow: initial clinical experience. J Thorac Cardiovasc Surg. 2003;126:1775-80.

21. Corno AF, Prosi M, Fridez P, Zunino P, Quarteroni A, von Segesser LK. The noncircular shape of FloWatch-PAB prevents the need for pulmonary artery reconstruction after banding. Computational fluid dynamics and clinical correlations. Eur J Cardiothorac Surg. 2006;29:93-9.

22. Corno AF, Ladusans EJ, Pozzi M, Kerr S. FloWatch ${ }^{\circledR}$ versus conventional pulmonary artery banding. J Thorac Cardiovasc Surg. 2007;134:1413-9.

23. Kalavrouziotis G, Karanasios E, Konstandopoulolu G, Paphitis C. Telemetrically adjustable pulmonary artery banding: first application in Greece. Hellenic J Cardiol. 2008;49:195-8.

24. Sekarski N, Fridez P, Corno AF, von Segesser LK, Meijboom E. Doppler guided regulation of a telemetrically operated adjustable pulmonary banding system. J Am Coll Cardiol. 2004;44:1087-94. 